\title{
Weshalb ich in der Schweiz gerne zum Arzt gehe
}

Eva Mell

Managing Editor der Schweizerischen Ärztezeitung

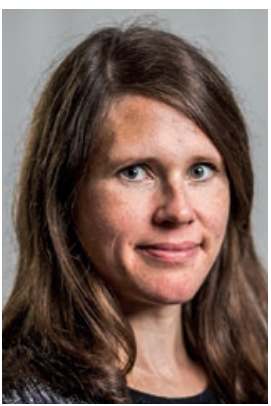

«Haben Sie eine Frage? Kann ich Ihnen noch etwas erklären?» - Ich erinnere mich genau, wie ich im Behandlungszimmer meines Arztes in der Schweiz sass und meinen Ohren kaum traute. Ich durfte wirklich noch eine Frage stellen? So viel ärztliche Zuwendung hatte ich selten erlebt.

Ich komme aus Deutschland. Mein Leben lang habe ich die Erfahrung gemacht: Ärztinnen und Ärzte haben keine Zeit. Fragen, die ich unbedingt stellen wollte, habe ich vor dem Arztbesuch innerlich so knapp wie möglich vorformuliert und in der Sprechstunde mit einer erhöhten Geschwindigkeit aus mir herausgestossen. Wenn ich mit einem Rezept in der Hand aus der Praxis ging, war mir längst nicht immer klar, weshalb die Behandlung auf diese Weise erfolgen musste.

Vor einigen Jahren begann ich als Redaktorin in der Schweiz zu arbeiten. Das Land hat mich als Journalistin von Anfang an begeistert: Die Entfernungen sind gering, die Vielfalt ist gross. Die Begegnungen mit den Menschen, über die ich schrieb, und die abwechslungsreichen Themen entschädigten mich für den bürokratischen Aufwand, den ich beim Stellenwechsel in die Schweiz hatte. Anfangs war ich geradezu genervt davon, mir eine Schweizer Krankenversicherung organisieren zu müssen. Doch mittlerweile ist die ärztliche Versorgung einer der schönsten Nebeneffekte meiner Berufstätigkeit hierzulande. Meine beiden Kinder sind in Schweizer Spitälern geboren. Meine ältere Tochter hatte als Baby eine grössere gesundheitliche Baustelle, die in einem Schweizer Unispital behandelt wurde, und hat momentan eine mittelgrosse Baustelle, die wieder regelmässig dazu führt, dass wir in Wartezimmern in der Schweiz Platz nehmen.

Zwei oder drei Tage, nachdem sie geboren wurde, sass ich im Frühstückssaal des Spitals. Eine andere Mutter rief auf einmal: «Ich will gar nicht mehr nach Hause. Ich fühle mich wie im Hotel und alle kümmern sich um mich!» An diesen Ausspruch musste ich bei meinen weiteren Spitalbesuchen in der Schweiz denken. Wann immer ich wegen Schmerzen, einer Frage oder Unsicherheit klingelte - schnell kam jemand und half mir geduldig. Die Mitarbeitenden nahmen sich die
Zeit, die ich als Patientin oder als Mutter einer Patientin von ihnen brauchte.

In deutschen Spitälern hingegen erlebte ich bisher vor allem Zeitdruck bei Ärztinnen, Ärzten und Pflegekräften und immer wieder Behandlungen, die mein Vertrauen ins Gesundheitssystem eher schmälerten.

Mir ist klar, dass ich bis hierhin stark polarisiert habe. Wie unjournalistisch! Deshalb möchte ich nun erwähnen, dass es auch in Deutschland schon vorkam, dass ich sehr zufrieden mit einer Behandlung war und manche Ärztinnen und Ärzte sehr schätze. Ausserdem habe ich von Schweizer Arbeitskolleginnen und -kollegen auch Kritik in Bezug auf das Schweizer Gesundheitssystem gehört. Zu wenig Zeit, zu unfreundlich, zu wenig patientenorientiert: Was ich in deutschen Arztpraxen und Krankenhäusern erlebt habe, scheinen manche Schweizerinnen und Schweizer auch bei ihren Arzt- und Spitalbesuchen zu erfahren.

\section{«Mittlerweile ist die ärztliche Versorgung einer der schönsten Nebeneffekte meiner Berufstätigkeit in der Schweiz.»}

Ich gebe zu, dass ich selbst auch nicht nur reibungslose Kontakte zu Ärztinnen und Ärzten in der Schweiz hatte. Ja, ich war begeistert, als mein Arzt mich ermutigte, eine Frage zu stellen. Doch mit genau dieser Person kam es einige Wochen später zu Kommunikationsproblemen, die auf beiden Seiten zu Verstimmungen führten. Worüber ich aber froh war und bin: Er nahm sich die Zeit, mit mir darüber zu sprechen, so dass wir die Behandlung im Reinen miteinander abschliessen konnten.

Nun bin ich Redaktorin bei der Schweizerischen Ärztezeitung und freue mich, einen tieferen Einblick in die Themen zu erhalten, die Ärztinnen und Ärzte in der Schweiz bewegen. Bereits nach wenigen Wochen in der Redaktion sehe ich, dass es viel Diskussionsbedarf rund um gesundheitspolitische Entwicklungen gibt, dass manches zu Recht kritisiert wird und verbessert werden muss. Dennoch: Lassen Sie sich an Ihrem heutigen Arbeitstag von einem Wort begleiten, das ich Ihnen nun mit auf den Weg geben möchte: «Danke!» 